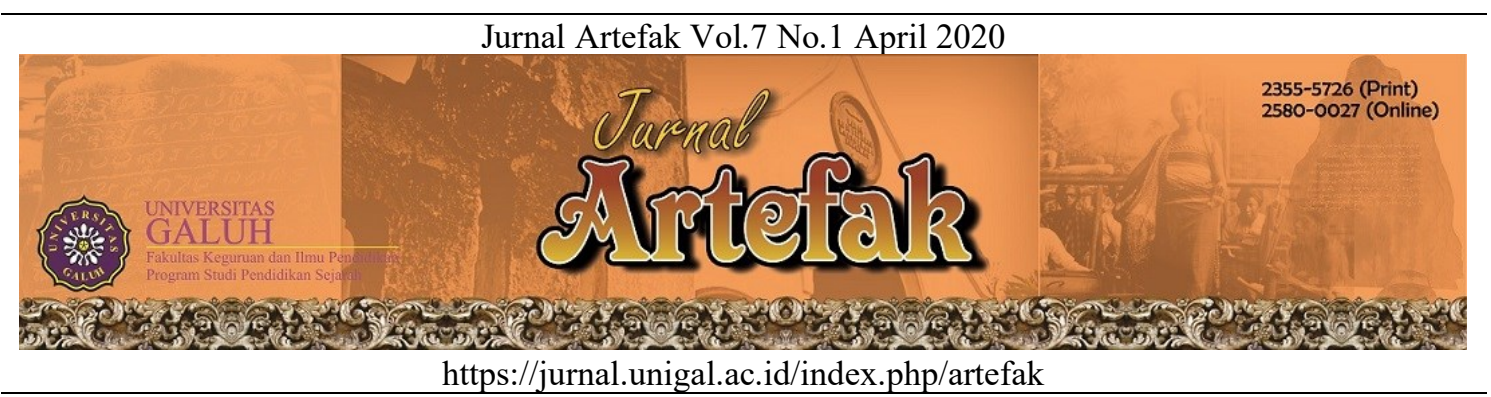

\title{
PENDIDIKAN PADA MASA PEMERINTAH KOLONIAL DI HINDIA BELANDA TAHUN 1900-1930
}

\author{
Alifia Nurhusna Afandi ${ }^{1}$, Aprilia Iva Swastika ${ }^{2}$, Ervin Yunus Evendi ${ }^{3}$ \\ Universitas Negeri Malang, Indonesia \\ E-mail: alifiafandi25@gmail.com, apriliaswstk@gmail.com, ervinyunus2@gmail.com \\ Sejarah Artikel: Diterima: 12-3-2020 Disetujui: 27-04-2020 Dipublikasikan: 30-4-2020
}

\begin{abstract}
Abstrak
Pada artikel ini membahas tentang pendidikan yang dilaksanakan pemerintahan kolonial di Hindia Belanda selama tahun 1900-1930 dimana diawali karena kritik dari berbagai pihak yang kemudian memunculkan politik etis kebijakannya antara lain emigrasi, edukasi, dan irigasi kebijakan politik etis seharusnya mampu memberikan kesempatan rakyat untuk menjadi lebih sejahtera karena salah satu kebijakannya adalah edukasi dengan adanya pendidikan merupakan awal untuk perubahan dan perkembangan dalam segala aspek. Tujuan penulisan artikel ini adalah untuk mengetahui apa yang melatarbelakangi pelaksanaan pendidikan pada masa pemerintahan kolonial tahun 1900-1930 serta pelaksanaan pendidikan pada masa pemerintahan kolonial tahun 1900-1930 Selain itu bertujuan untuk mengetahui perbedaan ataupun persamaan model pendidikan masa pemerintahan kolonial dengan sekarang, dan untuk membuka wawasan penulis serta pembaca tentang proses munculnya sistem pendidikan formal bagi masyarakat pribumi pada masa pemerintahan kolonial serta bagaimana pelaksanaanya. Untuk mengetahui yang melatarbelakangi dan bagaimana pelaksanaan pendidikan yang diterapkan pemerintahan kolonial Belanda maka dalam artikel ini menggunakan metode studi pustaka dengan menelaah atau mengeksplorasi beberapa buku, jurnal, maupun dokumen baik cetak maupun elektronik yang dianggap revelan dengan kajian yang dilakukan. Hasilnya pada periode 1900 hingga 1930 pendidikan di Indonesia mengalami kemajuan dimana pendidikan yang pada awalnya dibatasi dengan kekuasaan pada waktu itu mulai melebur penduduk pribumi memiliki kesempatan untuk bisa melanjutkan ke sekolah lanjutan bahkan hingga sekolah tinggi walaupun masih terdapat pendiskriminasian selain itu juga muncul beberapa sekolah dasar berbahasa belanda bagi pribumi 1900-an anak rakyat biasa mulai dikenalkan dengan bahasa belanda di beberapa sekolah namun tetap dengan catatan setiap jenjangnya selalu ada perbedaan.
\end{abstract}

Kata Kunci: Pendidikan, Hindia Belanda, Pemerintah kolonial Belanda, politik etis

This article talking about education carried out by Dutch Government in Dutch East Indies during 19001930 caused by criticisms from various parties that bring out ethical politic. Its policies are emigration, education, and immigration. Ethical Politic's policies should be able to give people opportunity become more prosperous, because one of the policies is education. Education is a beginning for change and development in all aspects. The purposes of this article are to find out the educational background in the 1900-1930 colonial government and the educational implementation in the 1900-1930 colonial government. Furthermore, the other purposes to find out the differences and the equations of education between during the Dutch Colonial and nowadays, and to open the readers and writer's insights about the process of the formal education system for natives during colonial and how to do it. According to those purposes, in this article the writer use literature review method by studying or exploring several books, journals, or documents wether it's printed or electronic that relevant to the study conducted. The results are, in the period 1900 until 1930 education in Indonesia progressed. Education that was intially restricted by power at that time start to dissolved. Natives had opportunity to continued to the secondary school even to the college in spite of the discrimination. Moreover, there were some elementary schools in Dutch for 1900s natives. Commoners' children began to be introduced to the Dutch language in several schools but still, in each level there were always differences.

Keyword: Education, Dutch East Indies, Dutch Colonial Government, ethical politics 


\section{PENDAHULUAN}

Kolonialisme merupakan suatu usaha untuk mengusai wilayah bangsa lain yang bertujuan untuk menguras atau mendapatkan sumber daya suatu bangsa yang di kuasai demi pengolahan industrialisasi di Negara kolonisator. Dalam hal ini kesejahteraan maupun pendidikan di daerah koloni tidak diperhatikan. Indonesia yang pada saat itu masih bernama Hindia Belanda pernah dikuasai oleh pemerintah kolonial Belanda,

Sejatinya menurut S. kutoyo dan Sri Soetjiatiningsih (1981) sebelum datangnya bangsa Barat ke Hindia Belanda, masyarakat di desa sudah mengenal pendidikan baik dari keluarga maupun dari lingkungan yang mana pendidikan dalam keluarga, peran orang tua lah yang sangat berpengaruh sehingga nantinya sang anak dapat menjadi pribadi yang dapat bermanfaat bagi dirinya sendiri, keluarga, dan lingkungannya. Selain itu kedatangan islam juga memberikan pengaruh pendidikan di Hindia Belanda pendidikan dilakukan di mushola dan pondok pesantren.

Dengan kedatangan bangsa Belanda ke Indonesia pendidikan yang diberikan membentuk masyarakat yang feodal, karena pendidikan yang diselenggarakan oleh pemerintah kolonial berdasarkan garis warna dan diskriminatif, prinsip ini dibedakan jenis dan tingkatan yang telah dibagi oleh pemerintah kolonial menjadi kelompokkelompok yaitu, kelompok Eropa,Timur Asing (Arab dan Cina), dan pribumi. Namun dalam praktinya penduduk pribumi masih terbagi menjadi golongan priyayi dan golongan pribumi biasa, perbedaan itu terjadi menurut golongan masyarakat dan status sosial. Selanjutnya perbedaan terssebut dipertegas dengan adanya penggunaan bahasa pengantar yaitu bahasa Belanda contohnya adalah Eerste Klasse School atau Sekolah Kelas Satu dengan bahasa Belanda sebagai bahasa pengantarnya (Djumhur dan Danasuparta,1974:146) untuk golongan Eropa dan elite pribumi, sedangkan bahasa Melayu untuk golongan pribumi biasa. Namun perubahan yang signifikan terjadi pada tahun 1900 hingga 1930 karena pemerintahan kolonial menerapkan politik etis yang didalamnya terdapat kebijakan edukasi, akan tetapi dalam praktinya tetap tidak mampu lepas dari kebijakan untuk kepentingan sendiri dan masih bersifat diskriminatif.

Maka berdasarkan uraian latar belakang diatas maka dapat ditarik pokok permasalahan yaitu: 1) Apakah yang melatarbelakangi pelaksanaan pendidikan pada masa pemerintahan kolonial tahun 1900-1930? 2) Bagaimana pelaksanaan pendidikan pada masa pemerintahan kolonial tahun 19001930 ?

Sehingga tujuan penulisan artikel ini untuk mengetahui apa yang melatarbelakangi pelaksanaan pendidikan pada masa pemerintahan kolonial tahun 1900-1930 serta pelaksanaan pendidikan pada masa pemerintahan kolonial tahun 1900-1930 karena sepanjang tahun tersebut ditetapkan politik etis yang salah satunya memperbolehkan penduduk pribumi untuk mengenyam pendidikan. Selain itu bertujuan untuk mengetahui perbedaan ataupun persamaan model pendidikan masa pemerintahan kolonial dengan sekarang, lalu juga untuk membuka wawasan penulis serta pembaca tentang proses munculnya sistem pendidikan formal bagi masyarakat pribumi pada masa pemerintahan kolonial serta bagaimana pelaksanaanya.

\section{METODE PENELITIAN}

Metode yang dilakukan dalam kajian ini adalah metode atau pendekatan kepustakaan yang mana dapat diartikan sebagai serangkaian kegiatan yang berkenaan dengan metode pengumpulan data pustaka, membaca, dan mencatat serta mengolah bahan kajian (Zed, 2003). Ataupun studi kepustakaan juga dapat diartikan sebagai teknik pengumpulan data dengan melakukaan penelaahan terhadap buku, literatur, catatat, serta berbagai laporan yang mana berkaitan 
dengan masalah yang ingin dipecahkan (Nazir, 1988) berdasarkan uraian tersebut maka dapat disimpulkan bahwa proses pengumpulan data dalam kajian ini dilakukan dengan menelaah atau mengeksplorasi beberapa buku, jurnal, maupun dokumen baik cetak maupun elektronik yang dianggap revelan dengan kajian yang dilakukan.

\section{HASIL PENELITIAN DAN PEMBAHASAN}

\section{Latar belakang Pelaksanaan Pendidikan Pemerintah Kolonial Tahun 1900-1930}

Berawal dari diterapkannya sistem tanam paksa (1830-1870) yang mendapatkan kritik dari berbagai golongan contohnya adalah seorang pendeta yang kemudian menjadi anggota parlemen yaitu Baron van Hoevell, membela Hindia Belanda dan memandang bahwa pemerintah kolonial harus memenuhi dan memerhatikan kepentingan masyarakat pribumi (A. Daliman, 2012). Dan politik liberal (1870-1900) yang menyebabakan kemiskinan melanda Hindia Belanda karena dengan bergabungnya perusahaan-perusahaan asing maka menghapus harapan rakyat untuk sejahtera.

Hal-hal tersebut menimbulkan kritik dari berbagai kalangan seperti yang ditulis oleh Multatuli (Douwes Dekker) dalam bukunya Max Havellar (1860) yang menceritakan kondisi masyarakat petani yang menderita akibat mendapat tekanan dari pemerintah kolonial. Selain itu aja Pada tahun 1899, artiikel karya Van Deventer terbit dalam majalah De Gids, dalam majalah De Gids ini memiliki judul Een Eereschuld aau "Hutang Kehormatan", artikel ini berisi tentang pemikiran Van Deventer mengenai keuntungan Hindia Belanda selama menjajah bangsa Indonesia dan hendaknya semua itu dibayar kembali dari perbendaharaan negara. Yang berarti hutang budi tentang kemakmuran yang diperoleh oleh Belanda adalah dari kerja keras dan jasa orang-orang pribumi dan
Belanda seharusnya menganggap itu sebagai hutang yang harus dibayar dengan menyelenggarakan trilogi atau trias yaitu irigasi, emigrasi, dan edukasi.

Dan Selanjutnya gagasan tersebut ditanggapi oleh Ratu Wilhelmina, tepatnya pada 17 September 1901 pemikiran dari Van Deventer ini dapat tertuang dalam pidato ratu Belanda yang berjudul Ethische Richting yang berarti Haluan Etis. Dalam pidato tersebut menegaskan pemerintah kolonial melakukan usaha-usaha untuk menanggulangi permasalahan kesejahteraan yang dialami masyarakat pribumi dengan dihidupkannya kembali bidang agraris dan industri, lalu juga dengan memberikan pinjaman tidak berbunga dengan jangka waktu tertentu, selain itu juga dengan pemberian hadiah. Pidato tersebutlah yang menandai awal dari kebijakan politik etis. (Kusmayadi: 145)

Setelah ratu Belanda mengambil pemikiran Van Deventer dan dimasukan kedalam pidato nya memunculkan ide atau ekspresi yang dipandang sebagai suatu ide baru atau praktek politk baru yang biasa disebut sebagai politik etis atau politik balas jasa. Namun politik etis ini sangat bertentangan dengan eksploitasi materi yang dilakukan pemerintahan Kolonial, karena politik etis ini lebih menonjolkan bahwa adanya sikap kewajiban moral bangsa yang mempunyai kebudayaan tinggi terhadap bangsa yang tertindas (Nasution: 15)

Namun sejatinya dalam pelaksanaan politik etis tidak bisa jauh dari kepentingan sepihak pemerintah kolonial yang takut mendapat banyak kritikan dan jika dibiarkan terus menerus maka ditakutkan akan timbul perlawanan dari masyarakat pribumi yang semakin lama semakin merasakan penderitaan. Kebijakan politik etis terdiri dari Irigasi yang terlihat dari adanya perbaikanperbaikan yang dilakukan namun dalam praktinya sarana irigasi bukanlah untuk kesejahteraan rakyat pribumi namun lebih terarahkan pada kepentingan ekonomi pemerintah kolonial. Lalu emigrasi yaitu 
memindahkan masyarakat pribumi yang berada pada pulau yang berpenduduk padat contohnya adalah Jawa kepulau yang bependuduk sedikit contohnya Kalimantan yang bertujuan untuk lahan baru dan mengelolanya. Namun pada kenyataannya tanah-tanah yang kosong telah dijadikan lahan menanam tebu dan tembakau dan masyarakat pribumi hanya dijadikan sebagai tenaga kerja di perkebunan tebu.

Tidak jauh berbeda dengan irigasi dan emigrasi, pelaksanaan edukasi juga secara tersirat adalah untuk kepentingan pemerintah kolonial hal tersebut dapat terlihat dari adanya diskriminasi yaitu terdapat dua macam sekolah yaitu Sekolah Ongko Siji untuk pribumi yang memiliki kedudukan dan Sekolah Ongko Loro yang diperuntukkan untuk masyarakat pribumi yang biasa karena tujuannya hanya untuk mendapatkan memenuhi pegawai rendahan maka pendidikan yang dilakukan juga hanya bertujuan untuk mendapatkan lulusan yang hanya dapat membaca, menulis, dan berhitung. Selain itu anggaran dana yang diberikan untuk pendidikan penduduk pribumi sangat sedikit, tercatat pada tahun 1905 termasuk dalam tunjangan sekolah swasta sebesar f 2 juta, sehingga apabila dibagi 40 juta penduduk maka hanya 5 sen per orang. (A. Daliman, 2012)

\section{Awal Pelaksanaan Pendidikan Untuk Bumiputera Masa Pemerintahan Kolonial Tahun 1900-1930}

Pada tahun 1899, artiikel karya Van Deventer terbit dalam majalah De Gids. Artikel tulisan Van Deventer memilik judul "Hutang Kehormatan", artikel ini berisi tentang pemikiran Van Deventer mengenai keuntungan Hindia Belanda selama menjajah bangsa Indonesia dan hendaknya semua itu dibayar kembali dari perbendaharaan negara. Dan akhirnya pada 1901 pemikiran dari Van Deventer ini dapat tertuang dalam pidato ratu Belanda (kusmayadi: 145)
Setelah ratu Belanda mengambil pemikiran Van Deventer dan dimasukan kedalam pidato nya memunculkan ide atau ekspresi yang dipandang sebagai suatu ide baru atau praktek politk baru yang biasa disebut sebagai politik etis atau politik balas jasa. Namun politik etis ini sangat bertentangan dengan eksploitasi materi yang dilakukan pemerintahan Kolonial, karena politik etis ini lebih menonjolkan bahwa adanya sikap kewajiban moral bangsa yang mempunyai kebudayaan tinggi terhadap bangsa yang tertindas (Nasution: 15)

Selain karena adanya model politik baru yakni politik etis pada abad ke 20 sendiri Belanda mengalami resesi ekonomi yang meluas, namun perekonomian liberal dan administrasi politik penjajahan di hindia belanda malah makin meluas. Dan membuat golongan bumiputera kesejahteraanya merosot terutama di jawa. Sehingga akhirnya pada 15 oktober 1902 dibentuk komisi penyidik (Mindere Welvaart Commissie).

Administrasi politik yang makin meluas, perekonomian yang makin meluas dan kesejahteraan golongan bumiputera yang merosot, tiga faktor ini yang menjadi dasar munculnya politik etis ala Van Deventer atau politik asosiasi ala snouck hurgronje saat menjelang abad 20. Inti politik ini adalah tanpa menjadi orang eropa atau barat tapi dapat memanfaatkan berkah bangsa barat. Hal ini sangat bermanfaat untuk perkembangan dunia pendidikan dan teknologi untuk golongan bumiputera.

Bagi seluruh penganut politik etis pendidikan pemegang peranan utama. Hal ini tercermin dalam trilogi pemerintah penjajahan yakni pendidikan, irigasi dan transmigrasi (educatie, irrigatie, emigratie). Dan bahasa belanda digunakan sebagai bahasa pengantar, dengan sistem ini golongan bumiputera kalangan atas atau anak para penjabat pro Belanda yang diuntungkan.

Dulu nya bahasa belanda didorong digunakan sebagai bahasa pengantar namun pada abad XX pergeseran pendidikan bersifat 
barat. Dan penggunaan bahasa belanda tidak lagi di dorong namun lebih karena perkembangan objektif dibidang ekonomi, politik dan sosial-budaya. Namun sosialbudaya perlu digaris bawahi karena kenyataan nya bahasa daerah dan melayu sudah tidak memainkan peran nya dalam penyampaian ilmu pengetahuan dan teknologi.

$$
\text { Cepatnya pergeseran pendidikan }
$$

bumiputera kesifat barat mendorong munculnya beberapa tokoh liberal pembaharu, terutama Mr. J.H Abendanon dan A.W.F Idenburg. Abandon menjabat sebagai direktur penidikan, agama, dan industri (1900-1905), Idenburg menjabat menteri jajahan (19021905).

Belum lama bertugas Abendanon sudah mampu mengurangi biaya sekolah bagi murid bumiputera yang bersekolah di ELS (sekolah dasar eropa). Melalui sekolah ini Abendon pun merancang pendidikan calon ibu yang baik untuk gadis di jawa. Salah satu yang memanfaatkan kesempatan pendidikan ini dengan baik adalah R.A Kartini, lalu beliau bersekolah di ELS Jepara.

Pada 1900 sebelum datangnya abendanon, sekolah raja dipertegas menjadi sekolah calon pegawai (Opleidingsschool voor indlansche ambtenaren-OSVIA) karena sulitnya menyampaikan hukum kepada pejabat bumiputera dalam bahasa pengantar melayu dan bahasa daerah, padahal masalah hukum mulai diserahkan kepada mereka. Akhirnya untuk mengatasi masalah ini sekolah raja dipertegas yakni mendidik calon pegawai menggunakan bahasa belanda tidak peduli anak pembesar atau tidak. Hal ini pun berdampak akhirnya yang bisa masuk hanya lulusan ELS atau sederajat. Dengan hal ini abendanon melihat, bila dengan kebijakan ini maka lulusan sekolah dasar kelas dua (tweede klase) sangat mustahil untuk bisa masuk OSVIA.Sehingga Abendanon pada 1903 mengizinkan calon murid OSVIA untuk masuk ELS secara gratis. Perubahan lain yang terjadi adalah sekolah guru di Bukit Tinggi pada 1904 abendanon dapat menetapkan bahasa belanda sebagai bahasa pengantar di dua kelas tertinggi.

\section{Pendidikan Dibawah Van Heutsz Dan Resesi Ekonomi}

Pada tahun 1904 muncul seorang gubernur jendral baru bernama J.B. Van Heutsz, dia adalah seorang pahlawan Belanda dalam Perang Aceh. Van Heutsz ingin merubah Pendidikan selama empat tahun agar lebih praktis, terutama untuk Bumiputra. Yang dimaksud praktis adalah dengan mendirikannya sekolah kejuruan. Didirikannya sekolah kerajinan rumah tangga oleh regent Ngawi R.M.T. Utoyo, khususnya yang memiliki keahlian mengolah bahan seperti, kayu, kulit, bambu, maupun anyaman.

Akan tetapi sistem pendidikan tidak mudah diubah menjadi arah yang lebih praktis. Oleh karena itu Dirk Fock pengganti Indenburg sebagai Menteri Jajahan meminta agar mengadakan penelitian bagi pendidikan. Tidak hanya untuk Sekolah Kejuruan tetapi juga sekoalah lainnya. Mr.J.G.Poot pengganti Abendanon menunjuk J.E.Jasper untuk memimpin penelitian tersebut. Pada April 1906 Jasper melaporkan tentang apa yang dikhawatirkan Snouck Hungronje terhadap Sekolah Kejuruan atau Sekolah Teknik yang belum memiliki tenaga kerja terdidik. Jika Bumiputra dididik oleh sekolah tersebut maka penyaluran hanya akan terbatas. Sedangkan hadirnya tenaga didik lama-kelamaan akan mendorong tumbuhnya jiwa wirausaha. Oleh karena itu perlu adanya peningkatan belajar Sekolah Kejuruan sekitar tiga tahun. Laporan dari Jasper juga berpendapat bahwa yang nantinya menjadi murid hanyalah lulusan kelas dua. Maka dikenal dua macam Sekolah Teknik yaitu "balai latihan" (ambachtsleergang) yang terbuka untuk lulusan Sekolah Dasar Kelas Dua, dan "Sekolah Teknik" (ambachschool) yang terbuka untuk lulusan ELS atau sederajat. Lama belajar "balai latihan" sekitar tiga tahun untuk mendidik muridnya menjadi kepala 
tukang, dan dua tahun untuk spesialisasi seperti tukang batu, mebel, montir, dan listrik.

Gubernur Jendral Van Heutsz membuat penelitian terhadap Sekolah Dasar Kelas Satu, apakah tujuan telah berfungsi sebagai pengembangan potensi dan tingkat peradaban anak-anak Bumiputra. Masa belajar Sekolah Dasar Kelas Satu ditingkatkan yang awalnya lima tahun menjadi enam tahun. Karena pendidikan bahasa Belanda yang kurang dikuasai, memerlukan peningkatan untuk pembelajaran bahasa Belanda. Sedangkan untuk Sekolah Dasar Kelas Dua masa belajarnya dikurangi karena terlalu mahal untuk anak Bumiputra yang belajarnya lima tahun menjadi tiga tahun. Setelah itu perlu dibangun Sekolah Rakyat (volkschool) atau disebut juga dengan Sekolah Desa (desaschool) untuk melayani orang yang ingin bersekolah yang masa belajarnya tiga tahun. Untuk peresmian Sekolah Desa terdapat tiga syarat, yaitu Sekolah Desa dibangun dan gurunya digaji rakyat desa, sedangkan pemerintah hanya membantu untuk sarana belajar dan uang. Syarat kedua pembangunan harus melewati masa percobaan. Syarat ketiga tidak boleh memaksa muridnya untuk bersekolah, Sekolah Desa diresmikan pada Maret 1906.Percobaan Sekolah Desa dilakukan di empat kabupaten yaitu, Priangan, Cirebon, Kedu, dan Kediri yang terjadi pada bulan Mei 1906. Percobaan Sekolah Desa tersebut berfungsi sebagai salah satunya upaya mengembalikan kemakmuran masyarakat Bumiputra. Setelah itu Sekolah Desa dilakukan di Aceh dan menyebar ke seluruh Nusantara yang menyebabkan $40 \%$ anak usia 6-9 tahun merasakan bersekolah.

\section{Tingkatan Pendidikan Pada Masa Kolonialisme Tahun 1900-1930}

Pada tahun 1904 muncul seorang gubernur jendral baru bernama J.B. Van Heutsz, dia adalah seorang pahlawan Belanda dalam Perang Aceh. Van Heutsz ingin merubah Pendidikan selama empat tahun agar lebih praktis, terutama untuk Bumiputra. Yang dimaksud praktis adalah dengan mendirikannya sekolah kejuruan. Didirikannya sekolah kerajinan rumah tangga oleh regent Ngawi R.M.T. Utoyo, khususnya yang memiliki keahlian mengolah bahan seperti, kayu, kulit, bambu, maupun anyaman.

Akan tetapi sistem pendidikan tidak mudah diubah menjadi arah yang lebih praktis. Oleh karena itu Dirk Fock pengganti Indenburg sebagai Menteri Jajahan meminta agar mengadakan penelitian bagi pendidikan. Tidak hanya untuk Sekolah Kejuruan tetapi juga sekoalah lainnya. Mr.J.G.Poot pengganti Abendanon menunjuk J.E.Jasper untuk memimpin penelitian tersebut. Pada April 1906 Jasper melaporkan tentang apa yang dikhawatirkan Snouck Hungronje terhadap Sekolah Kejuruan atau Sekolah Teknik yang belum memiliki tenaga kerja terdidik. Jika Bumiputra dididik oleh sekolah tersebut maka penyaluran hanya akan terbatas. Sedangkan hadirnya tenaga didik lama-kelamaan akan mendorong tumbuhnya jiwa wirausaha. Oleh karena itu perlu adanya peningkatan belajar Sekolah Kejuruan sekitar tiga tahun. Laporan dari Jasper juga berpendapat bahwa yang nantinya menjadi murid hanyalah lulusan kelas dua. Maka dikenal dua macam Sekolah Teknik yaitu "balai latihan" (ambachtsleergang) yang terbuka untuk lulusan Sekolah Dasar Kelas Dua, dan "Sekolah Teknik" (ambachschool) yang terbuka untuk lulusan ELS atau sederajat. Lama belajar "balai latihan" sekitar tiga tahun untuk mendidik muridnya menjadi kepala tukang, dan dua tahun untuk spesialisasi seperti tukang batu, mebel, montir, dan listrik.

Gubernur Jendral Van Heutsz membuat penelitian terhadap Sekolah Dasar Kelas Satu, apakah tujuan telah berfungsi sebagai pengembangan potensi dan tingkat peradaban anak-anak Bumiputra. Masa belajar Sekolah Dasar Kelas Satu ditingkatkan yang awalnya lima tahun menjadi enam tahun. Karena pendidikan bahasa Belanda yang kurang dikuasai, memerlukan peningkatan untuk pembelajaran bahasa Belanda. Sedangkan 
untuk Sekolah Dasar Kelas Dua masa belajarnya dikurangi karena terlalu mahal untuk anak Bumiputra yang belajarnya lima tahun menjadi tiga tahun. Setelah itu perlu dibangun Sekolah Rakyat (volkschool) atau disebut juga dengan Sekolah Desa (desaschool) untuk melayani orang yang ingin bersekolah yang masa belajarnya tiga tahun. Untuk peresmian Sekolah Desa terdapat tiga syarat, yaitu Sekolah Desa dibangun dan gurunya digaji rakyat desa, sedangkan pemerintah hanya membantu untuk sarana belajar dan uang. Syarat kedua pembangunan harus melewati masa percobaan. Syarat ketiga tidak boleh memaksa muridnya untuk bersekolah, Sekolah Desa diresmikan pada Maret 1906.Percobaan Sekolah Desa dilakukan di empat kabupaten yaitu, Priangan, Cirebon, Kedu, dan Kediri yang terjadi pada bulan Mei 1906. Percobaan Sekolah Desa tersebut berfungsi sebagai salah satunya upaya mengembalikan kemakmuran masyarakat Bumiputra. Setelah itu Sekolah Desa dilakukan di Aceh dan menyebar ke seluruh Nusantara yang menyebabkan $40 \%$ anak usia 6-9 tahun merasakan bersekolah.

\section{Tingkatan Pendidikan Pada Masa Kolonialisme Tahun 1900-1930}

\section{1) Sekolah dasar berbahasa belanda untuk bumiputera}

Pada 16 februari 1914 keluarlah keputusan yang menetapkan perubahan untuk sekolah dasar de eerste klasse menjadi HIS (Holland inlandsche School) yang lama belajarnya selama tujuh tahun dan berbahasa belanda, sekolah ini diperuntukkan untuk anak kalangan elite pribumi.

Dan di desa pun juga terdapat sekolah yang bernama sekolah desa (volkschool) dan dalam pendidikannya berlangsung tiga tahun dengan menggunakan bahasa daerah sebagai bahasa pengantar Setelah 8 tahun berjalan para lulusan sekolah desa merasa tidak puas dengan tingkat pendidikan yang sudah diperoleh dan ingin melanjutkan namun mereka tidak memenuhi persyaratan. Hingga akhirnya pada 1915 pemerintah pun membentuk sekolah baru yang diberi nama vervolgschool dengan lama belajar dua tahun dan mempersiapkan lulusan sekolah desa untuk melanjutkan ke sekolah kejuruan.

Namun ternyata yang memerlukan pendidikan lanjutan bukan hanya sekolah desa namun HIS juga memerlukan sekolah lanjutan sehingga dibentuk lah MULO dan resmi menjadi sekolah pada 1914. Dan yang boleh melanjutkan ke MULO adalah lulusan sekolah rendah, kecuali sekolah desa.

Pada tahun 1920 K.F. Creutszberg, Direktur Pendidikan, Agama dan Industri beliau memiliki ide untuk membuat sekolah yang menghubungkan langsung antara sekolah desa dengan MULO dan tercetuslah ide membuat sekolah yang bernama Schakel School. Tujuan dari sekolah ini adalah untuk memperoleh pengetahuan yang lebih tinggi setelah tamat dari sekolah desa terutama dalam berbahasa belanda.

Masa belajar schakel school sendiri adalah lima tahun, setelah sekolah desa tiga tahun. Jadi, masa belajar seluruhnya delapan tahun dan dianggap setara dengan H.I.S. Peranan sekolah Schakel tidak kecil karena berfungsi sebagai jembatan penghubung antara sekolah desa dengan pendidik barat.

Dengan adanya Schakel School ini maka perbedaan kelas masyarakat untuk memasuki sekolah Barat telah lenyap dan bahasa Belanda yang selama ini dianggap sebagai jurang pemisah telah berhasil dijembatani. Setelah terbukanya H.I.S untuk anak-anak pribumi maka mereka dapat melanjutkan ke sekolah menengah, terutama ke M.U.L.O. Dan tamatan dari sini dapat memasuki sekolah kejuruan. Dengan demikian, mereka dapat menduduki posisi yang baik di dalam masyarakat dimana sebelumnya diduduki oleh orang Belanda.

\section{2) Sekolah lanjutan}

Beberapa kalangan melihat MULO saja belum cukup dan perlu ada sekolah lanjutan hingga pada 1915 komisi yang dipimpin prof dr. J, Woltjer mengusulkan untuk dibentuknya 
sekolah menengah untuk bumiputera dengan nama indische middelbare school yang dianggap sama dengan tiga kelas tertinggi HBS dan lebih terkenal dengan sebutan AMS (Algemeene middlebare school) dengan lama belajar tiga tahun. AMS memiliki dua jurusan yakni (Afdeeling) A, untuk pengetahuan kebudayaan atau humaniora. Dan jurusan A sendiri dibagi lagi menajdi dua yakni A1 untuk sastra dan humaniora timur, A2 untuk klasik barat. Dan untuk jurusan (Afdeeling) B untuk pengetahuan pasti dan alam.

Tamatan M.U.L.O dapat melanjutkan ke HBS. Dengan waktu lima tahun dan menduduki kelas IV. Baik M.U.L.O maupun HBS sebenarnya dipersiapkan untuk melanjutkan ke jenjang kejuruan. Orang yang memiliki ijazah M.U.L.O memiliki arti penting karena mendapat posisi baik di dalam masyarakat.

Selanjutnya AMS pun mengadakan pendidikan pertamanya pada tahun 1919 di Yogyakarta lengkap dengan dua jurusanya. Dan 1920 AMS juga mengadakan pendidikan di Bandung tapi hanya untuk jurusan A2. Dan 1926 AMS dengan jurusan sastra dan humaniora timur didirikan di Surakarta 1926. Kemudian sejak berdirinya A.M.S. sebagai lanjutan dari M.U.L.O. maka kesempatan untuk memasuki Perguruan Tinggi terbuka.

\section{3) Sekolah tinggi}

Kemudian munculah sekolah tinggi yang pertama di Hindia Belanda untuk Teknik yang bersatatus swasta yaitu Technische Hoogeschool te Bandung pada Juli 1920 yang disusul dengan sekolah tinggi kedokteran dan sekolah tinggi hukum.

Sekolah tinggi terbagi menjadi tiga, yaitu: Kedokteran Batavia 1927, ITB 1920, dan Recht Hoge School 1924.

Dengan berdirinya sekolah tinggi ini maka lengkap sudah jenjang pendidikan yang ada di Hindia Belanda, walaupun dalam seluruh jenjang masih terdapat perbedaan dan pemilihan, perbedaan antar golongan berdasarkan status masyarakat dan kelas sosial dan pemilihan secara bahasa namun hal inilah yang nantikan menjadi tonggak bangkitnya kebangsaan Indonesia.

\section{KESIMPULAN}

Proses pendidikan yang berlangsung di Hindia Belanda adalah salah satu titik awal munculnya tokoh kebangkitan bangsa. Pendidikan di Hindia Belanda sendiri diawali karena kritik dari beberapa tokoh dan golongan dengan diterapkan nya tanam paksa dan politik liberal, karena dalam kebijakan ini menimbulkan banyak penderitaan dan kemiskinan rakyat. Dan hal ini harus dibayar dengan menyelenggarakan trias yaitu irigasi, emigrasi, dan edukasi. Kritikan ini pun akhirnya di setujui ratu Belanda, dan pendidikan pun mulai digelar namun pendidikan berjalan dengan diskriminasi karena terdapat sekolah yang membedakan kelas anatara anak elite bangsawan atau tokoh yang pro Belanda dengan anak rakyat biasa. Dan hal ini karena anak bangsawan atau tokoh pro belanda ini nantinya akan bekerja untuk membantu Belanda. Dan anak rakyat biasa hanya menjadi pekerja kasar atau rendahan.

Namun pada periode 1900 hingga 1930 pendidikan di Indonesia mengalami kemajuan dimana pendidikan yang pada awalnya dibatasi dengan dengan kekuasaan pada waktu itu mulai melebur. Yang pada saat itu hanya lulusan HIS saja yang boleh melanjutkan ke sekolah lanjutan namun pada selang waktu setelahnya muncul lah beberapa sekolah dasar berbahasa belanda bagi lulusan sekolah desa contohnya vervolschool dan Schakel School dengan demikian mereka memiliki kesempatan untuk bisa melanjutkan ke sekolah kejuruan atau lanjutan walaupun masih terdapat pendiskriminasian.

Dengan munculnya beberapa sekolah dasar berbahasa belanda bagi pribumi hal inilah yang menjadi titik awal perkembangan pendidikan bagi anak pribumi. Yang dulunya anak rakyat biasa hanya bisa sekolah sampai sekolah desa namun pada 1900-an anak rakyat biasa mulai dikenalkan dengan bahasa belanda 
di beberapa sekolah sehingga bukan tidak mungkin lagi melanjutkan ke sekolah lanjutan bahkan hingga ke sekolah tinggi. Namun dengan catatan setiap jenjangnya selalu ada perbedaan dan pemilihan antar status dan golongan. Namun tetap hal inilah yang nanti mendorong munculnya beberapa tokoh kebangkitan nasional yang memiliki pemikiran luas yang mau membela rakyat Indonesia untuk merdeka. Dan menjadi titik awal perjuangan bangsa Indonesia menuju proses merdeka.

\section{DAFTAR PUSTAKA}

A, Daliman. 2012. Sejarah Indonesia Abad XIX-Awal abad XX. Yogyakarta: Ombak.

Djumhur dan Danasuparta. 1974. Sejarah Pendidikan. Bandung: Departemen Pendidikan dan Kebudayaan.

Kusmayadi Yadi. 2017. Sejarah Perkembangan Pendidikan di Priangan 1900-1942.

(Online)(https://jurnal.unigal.ac.id/ind ex.php/artefak/article/view/908).

Diakses pada 11 November 2019 pukul $18.00 \mathrm{WIB}$

Nazir, M. 1988. Metode Penelitian. Jakarta: Ghalia Indonesia.

Nasution. 1987. Sejarah Pendidikan Indonesia. Bandung: Jemmars

Nasution S. 2016. Strategi Pendidikan Belanda Pada Masa Kolonial di Indonesia.

(Online)(http://www.jurnal.uinsu.ac.id/ index.php/ihya/article/view/431/333).

Diakses pada 11 November 2019 pukul 19.00 WIB.

Simbolon Parakri T. 1995. Akar-akar kebangsaan Indonesia. Jakarta: Kompas.

S. Kutoyo dan Sri Soetjiatingsih. 1981. Sejarah Nasional Indonesia (jilid V). Jakarta: Pt.Grafitas

Zed, M. 2014. Metode Penelitian Kepustakaan. Jakarta: Yayasan Pustaka Obor Indonesia. 
Jurnal Artefak:

Vol.7 No.1 April 2020 [21-30]

Halaman | 30 